(2) Open Access Full Text Article

\title{
Acetazolamide-induced cilio-choroidal effusion after cataract surgery: unusual posterior involvement
}

\section{Romualdo Malagola \\ Loredana Arrico \\ Rossella Giannotti \\ Luigi Pattavina}

Department of Ophthalmology, University of Rome "La Sapienza," Rome, Italy
Correspondence: Loredana Arrico Department of Ophthalmology, University of Rome "Sapienza," Viale del Policlinico I55m, 0016I Rome, Italy Tel +39335 6900888

Email loredana.arrico@uniromal.it

\author{
This article was published in the following Dove Press journal: \\ Drug Design, Development and Therapy \\ 22 January 2013 \\ Number of times this article has been viewed
}

\begin{abstract}
Idiosyncratic reactions to a large number of drugs have been reported to cause choroidal detachment and secondary angle-closure glaucoma (ACG). We report a case of bilateral acute ACG and peculiar choroidal effusion following administration of oral acetazolamide immediately after cataract surgery. Few cases of acute secondary ACG with choroidal effusion and anterior shift of the lens-iris diaphragm have been associated with acetazolamide compared with other sulfonamides. As far as we are aware, posterior involvement with retinal folds and papillary edema due to acetazolamide has not been described before.
\end{abstract}

Keywords: acetazolamide, cilio-choroidal effusion, acute ACG, papillary edema, retinal folds

\section{Introduction}

Acetazolamide, a sulfonamide-derived medication, is frequently used in patients after cataract surgery. ${ }^{1}$

It is a member of the class of antihypertensive drugs and is specifically indicated in the treatment of glaucoma, epilepsy, benign intracranial hypertension (pseudotumor cerebri), altitude sickness, cystinuria, and ectasia. ${ }^{2-4}$ Acetazolamide acts as an inhibitor of the enzyme carbonic anhydrase and is therefore applied in ophthalmology to control primary or postsurgical secondary ocular hypertension. ${ }^{5}$

This medication and other sulfa drugs have been documented to cause, very rarely, idiosyncratic reactions characterized by transient myopia, ciliary body edema, uveal effusions, and anterior rotation of the lens-iris diaphragm, which causes secondary angleclosure glaucoma (ACG). ${ }^{6}$ Unfortunately, the angle closure occurs without pupillary block, so that topical miotics and peripheral iridectomy are not helpful. ${ }^{7}$ In contrast, stopping the offending agent and controlling the intraocular pressure (IOP) with the administration of drugs allows rapid resolution of signs and symptoms. This reaction has been frequently documented after topiramate administration, an antiepileptic agent also used to treat migraine, ${ }^{8,9}$ while only rarely after acetazolamide. ${ }^{10-12}$

Here, we report a case of ciliary body edema after administration of acetazolamide causing bilateral ACG, as already described in the literature. ${ }^{11,12}$ However, in our case we found a massive choroidal effusion with posterior retinal folds and papillary edema. The existent literature reporting ciliary body edema after administration of acetazolamide do not describe these features at the posterior pole. ${ }^{6-13}$

\section{Case report}

A 71-year-old white male had routine cataract surgery and intraocular lens implantation under local anesthetic in his right eye (RE) in the late afternoon. He was prescribed a 


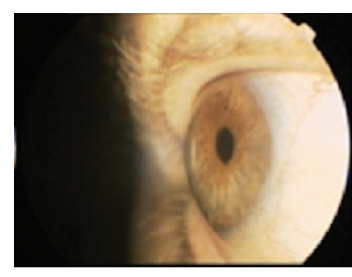

OD

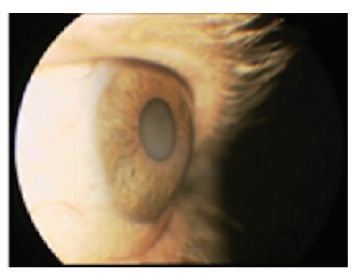

os
Figure I Anterior segment of the left and right eye (which underwent cataract surgery) showing the absence of the anterior chamber, observed during slit lamp examination, and choroidal congestion.

Abbreviations: OD, oculus dexter; OS, oculus sinister.

single oral dose of acetazolamide $(250 \mathrm{mg})$ before sleeping to prevent rise of IOP. The patient took the acetazolamide pill at 11 pm (4 hours after cataract surgery). About 3 hours later, he woke up because of severe pain and found he had reduced vision in both eyes, so was referred to our first-aid hospital.

Upon examination, the patient's best-corrected visual acuity was $3 / 50$ in the RE and 2/50 in left eye (LE), with corrections of $-4.50 \mathrm{D}$ in the RE and $-1.25 \mathrm{D}$ in the LE. Both eyes showed congestion and edema of the inferior bulbar conjunctiva, heavy cloudy cornea, and a very shallow anterior chamber (Figure 1). The intraocular lens was shifted forward. IOP was $52 \mathrm{mmHg}$ in the RE and $60 \mathrm{mmHg}$ in the LE. Gonioscopy revealed 360-degree appositional angle closure with a convex iris configuration in both eyes. Fundus examination was impossible due to opaque media. A diagnosis of ACG was made and the patient was admitted to the hospital. He was immediately administered mannitol $2 \mathrm{mg} / \mathrm{kg}$ intravenously and acetazolamide orally, together with topical steroids and $\beta$-blockers.

Later in the morning, his IOP was $32 \mathrm{mmHg}$ in the RE and $36 \mathrm{~mm} \mathrm{Hg}$ in the LE. Nd:YAG laser iridotomy was performed in the LE, but had a poor effect on anterior chamber depth and ocular hypertension.

B-scan ultrasonography (Figure 2) showed bilateral choroidal effusion with forward displacement of the anterior segment. Fundus examination was characterized by bilateral peripheral choroidal detachment (Figure 3) and papillary swelling. Posterior optical coherence tomography scans confirmed papillary edema (Figure 4) together with retinal folds and nerve fiber layer thickening.

Acetazolamide was suspected as the cause of the bilateral angle closure, thus was discontinued. The clinical

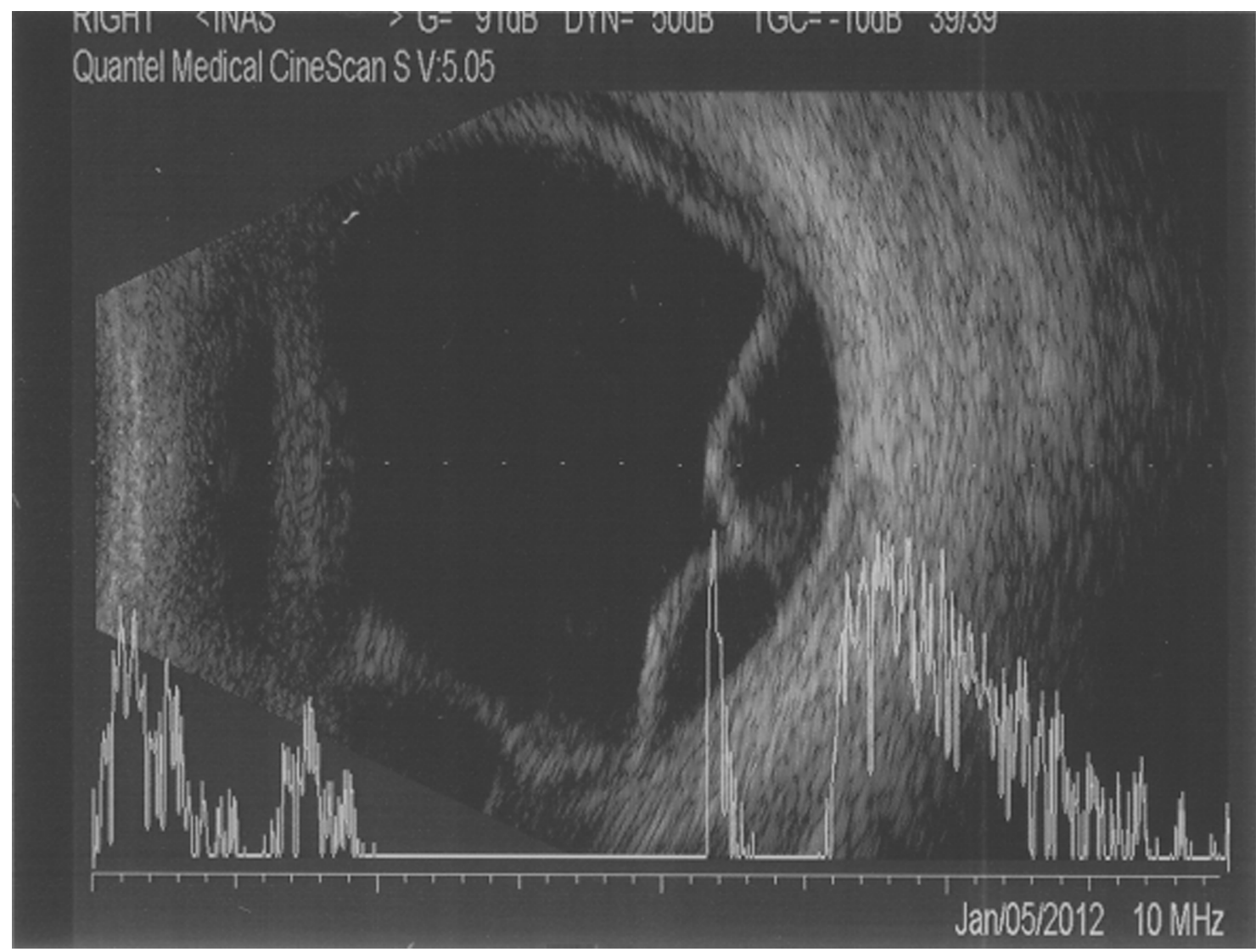

Figure 2 B-scan ultrasonography showing choroidal effusion and chorioretinal detachment. 


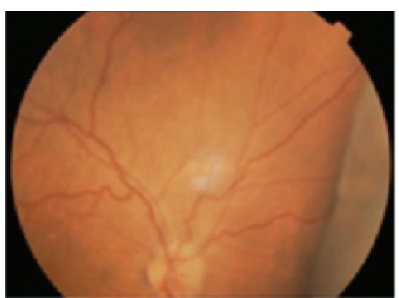

OD

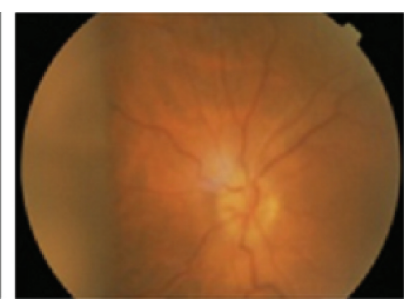

OS
Figure 3 Choroidal detachment observed during fundus examination using indirect Schepens ophthalmoscopy.

Abbreviations: OD, oculus dexter; OS, oculus sinister.

manifestations gradually improved and, 3 days later, the patient's IOP was $14 \mathrm{mmHg}$ in the RE and $16 \mathrm{mmHg}$ in the LE, his best-corrected visual acuity was 10/10 in the RE and $7 / 10$ in the LE (because of pre-existing lens opacities), and the myopic shift had receded.

A month later, the patient underwent cataract surgery of the LE without the use of any sulfonamide medication and, as evidenced by optical coherence tomography scans, had no complications.

\section{Discussion}

Few cases of acute secondary ACG with choroidal effusion and anterior shift of the lens-iris diaphragm have been associated with acetazolamide compared with other sulfonamides ${ }^{6,10-12}$ and there have been only a few reports of posterior retinal-fold involvement due to topiramate and hydrochlorothiazide. ${ }^{13,14}$ As far as the authors are aware, papillary edema has never been reported associated with sulfa drugs and posterior involvement with retinal folds and papillary edema due to acetazolamide has not been described.

The retinal folds in our patient were caused by the action of the retinal pigment epithelium inhibiting further progression of fluid from the choroidal space into the retina and inextensible scleral coat. His papillary edema was caused by the absence of any barrier in the prelaminar region that could inhibit the diffusion of fluid from the choroid into the

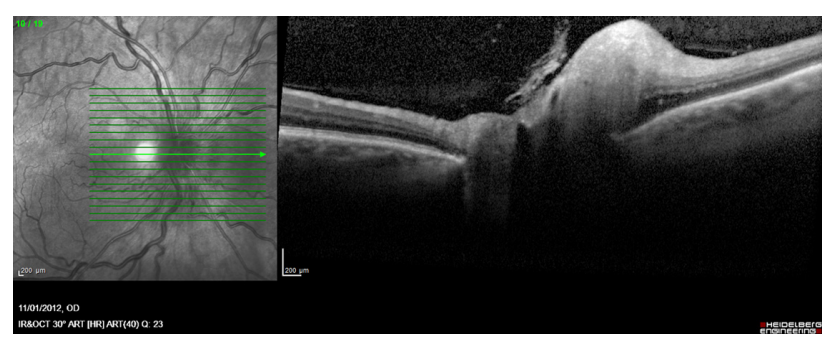

Figure 4 Papillary edema and nerve fiber layer thickening observed during optical coherence tomography examination (right eye). papilla and peripapillary region. This fluid diffusion was also responsible for the nerve fiber layer thickening.

Acetazolamide can cause a paradoxical adverse reaction, provoking cilio-choroidal effusion and massive involvement of the anterior and posterior segment. ${ }^{6-14}$

Although topical formulations of carbonic anhydrase enzyme inhibitors, such as dorzolamide, have been developed, ${ }^{15}$ we chose to administer oral acetazolamide because of its well-known ability to reduce acute elevated IOP. As acute elevated IOP is sight threatening, this justified the administration of the acetazolamide, with its associated risk of rare ocular and systemic side effects. Indeed, topical dorzolamide acts only on the carbonic anhydrase enzymes present in ciliary processes of the eye, reducing aqueous flow by $17 \%$ and IOP by up to $23 \%$ as monotherapy. ${ }^{16-19}$ In contrast, acetazolamide alone reduces these parameters by $30 \%{ }^{16-19}$ thanks to its diuretic properties and indirect osmotic effect that leads to vitreous dehydration together with hyperosmotic agents. Furthermore, it has been shown to act on the outward permeability of the blood-retina barrier. ${ }^{20}$

In prescribing acetazolamide, all specialists and general practitioners should be aware of this side effect of the drug and refer patients to ophthalmologists. At the same time, ophthalmologists should be able, by obtaining an accurate case history, to make a correct differential diagnosis between primary acute $\mathrm{ACG}$ and this rare secondary pharmacological adverse reaction.

\section{Disclosure}

The authors declare no conflicts of interest in this work.

\section{References}

1. Fogagnolo P, Centofanti M, Figus M, et al. Short-term changes in intraocular pressure after phacoemulsification in glaucoma patients. Ophthalmologica. 2012;228(3):154-158.

2. Kassamali R, Sica DA. Acetazolamide: a forgotten diuretic agent. Cardiol Rev. 2011;19(6):276-278.

3. Leaf DE, Goldfarb DS. Mechanisms of action of acetazolamide in the prophylaxis and treatment of acute mountain sickness. J Appl Physiol. 2007;102(4):1313-1322.

4. Celebisoy N, Gökçay F, Sirin H, Akyürekli O. Treatment of idiopathic intracranial hypertension: topiramate vs acetazolamide, an open-label study. Acta Neurol Scand. 2007;116(5):322-327.

5. Carta F, Scozzafava A, Supuran CT. Sulfonamides: a patent review (2008 - 2012). Expert Opin Ther Pat. 2012;22(7):747-758.

6. Lee GC, Tam CP, Danesh-Meyer HV, Myers JS, Katz LJ. Bilateral angle closure glaucoma induced by sulphonamide-derived medications. Clin Experiment Ophthalmol. 2007;35(1):55-58.

7. Lachkar Y, Bouassida W. Drug-induced acute angle closure glaucoma. Curr Opin Ophthalmol. 2007;18(2):129-133.

8. Desai CM, Ramchandani SJ, Bhopale SG, Ramchandani SS. Acute myopia and angle closure caused by topiramate, a drug used for prophylaxis of migraine. Indian J Ophthalmol. 2006;54(3):195-197. 
9. Fraunfelder FW, Fraunfelder FT, Keates EU. Topiramate-associated acute, bilateral, secondary angle-closure glaucoma. Ophthalmology. 2004;111(1):109-111.

10. Mancino R, Varesi C, Cerulli A, Aiello F, Nucci C. Acute bilateral angle-closure glaucoma and choroidal effusion associated with acetazolamide administration after cataract surgery. J Cataract Refract Surg. 2011;37(2):415-417.

11. Parthasarathi S, Myint K, Singh G, Mon S, Sadasivam P, Dhillon B. Bilateral acetazolamide-induced choroidal effusion following cataract surgery. Eye (Lond). 2007;21(6):870-872.

12. Senthil S, Garudadri C, Rao HB, Maheshwari R. Bilateral simultaneous acute angle closure caused by sulphonamide derivatives: a case series. Indian J Ophthalmol. 2010;58(3):248-252.

13. Guier CP. Elevated intraocular pressure and myopic shift linked to topiramate use. Optom Vis Sci. 2007;84(12):1070-1073.

14. Roh YR, Woo SJ, Park KH. Acute-onset bilateral myopia and ciliochoroidal effusion induced by hydrochlorothiazide. Korean $J$ Ophthalmol. 2011;25(3):214-217.
15. Mincione F, Scozzafava A, Supuran CT. The development of topically acting carbonic anhydrase inhibitors as antiglaucoma agents. Curr Pharm Des. 2008;14(7):649-654.

16. Sugrue MF. The pharmacology of antiglaucoma drugs. Pharmacol Ther. 1989;43(1):91-138.

17. Supuran CT. Carbonic anhydrases: novel therapeutic applications for inhibitors and activators. Nat Rev Drug Discov. 2008;7(2):168-181.

18. Sugrue MF. Pharmacological and ocular hypotensive properties of topical carbonic anhydrase inhibitors. Prog Ret Eye Res. 2000;19(1):87-112.

19. Maus TL, Larsson LI, McLaren JW, Brubaker RF. Comparison of dorzolamide and acetazolamide as suppressors of aqueous humor flow in humans. Arch Ophthalmol. 1997;115(1):45-49.

20. Takahashi J, Mori F, Hikichi T, Yoshida A. Effect of acetazolamide on outward permeability of blood-retina barrier using differential vitreous flyorophotometry. Curr Eye Res. 2001;23(3):166-170.

\section{Publish your work in this journal}

Drug Design, Development and Therapy is an international, peerreviewed open-access journal that spans the spectrum of drug design and development through to clinical applications. Clinical outcomes, patient safety, and programs for the development and effective, safe, and sustained use of medicines are a feature of the journal, which has also been accepted for indexing on PubMed Central. The manuscript management system is completely online and includes a very quick and fair peer-review system, which is all easy to use. Visit http://www.dovepress.com/testimonials.php to read real quotes from published authors.

Submit your manuscript here: http://www.dovepress.com/drug-design-development-and-therapy-journal 